\title{
ULTRA-SMOOTH DRY ETCHING OF GaAS USING A HYDROGEN PLASMA PRETREATMENT
}

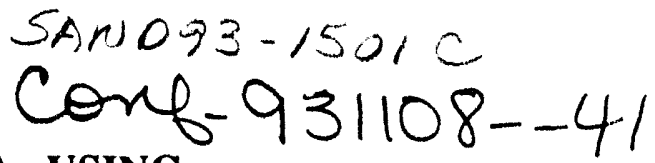

\author{
R. J. SHUL*, KENT D. CHOQUETTE*, A. J. HOWARD*, D. J. RIEGER*, C. A. \\ DiRUBIO*, R. S. FREUND**, AND R. C. WETZEL ${ }^{* *}$ \\ *Sandia National Laboratories, MS 0603, Albuquerque, NM 87185-0603 \\ **AT\&T Bell Laboratories, 6300 Mountain Avenue, Murray Hill, NJ 07974
}

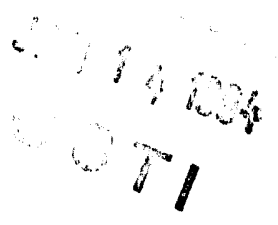

\begin{abstract}
We have attained extremely smooth etched surfaces on GaAs using a hydrogen plasma pretreatment before etching. The resultant morphology exhibits smooth surfaces since the etching proceeds uniformly through the GaAs without micromasking effects arising from a nonuniform surface oxide. We report the effects of hydrogen plasma treatments before RIE of GaAs in two different reactors using a $\mathrm{SiCl}_{4}$ plasma. Optimization of $\mathrm{H}_{2}$ plasma pretreatments has produced improvements in RMS roughness greater than 1 order of magnitude (22.4 to $1.51 \mathrm{~nm})$.
\end{abstract}

\section{INTRODUCTION}

Typically at the start of reactive ion etching (RIE), there is an initiation period during which no GaAs etching occurs. Only after penetration of the native oxides on the surface will etching begin. Moreover, even with a short initiation period, micromasking effects due to nonuniform oxide thickness can lead to a roughening of the etched surface. Therefore, removing the native oxide before RIE should lead to greater process control and uniformity, as well as insuring a smooth etched surface necessary for epitaxial regrowth or uniform metal contacts.

Hydrogen plasmas have been previously shown to selectively remove native oxides from GaAs [1-3]. We have used a hydrogen plasma treatment before dry etching to remove the surface oxides. We discuss the effects of a hydrogen plasma pretreatment before etching with a $\mathrm{SiCl}_{4}$ plasma; the GaAs surface roughness is characterized using scanning electron microscopy and atomic force microscopy.

\section{EXPERIMENTAL}

The GaAs wafers used in this study are two inch diameter semi-insulating substrates. The photoresist etch mask is approximately $1.4 \mu \mathrm{m}$ thick AZ-5214 with circular mesa features ranging in diameter from 4 to $32 \mu \mathrm{m}$ on $250 \mu \mathrm{m}$ pitch. The samples are $1 \mathrm{~cm}^{2}$ to minimize loading effects. The etched surface morphology is quantified using a Digital Instruments atomic force microscope (AFM) operating in air in contact mode. The data is reported as RMS surface 
roughness which represents the standard deviation of the roughness values within a $2500 \mu \mathrm{m}^{2}$ area.

RIE etches were performed at Sandia National Laboratories, Albuquerque (SNL) and AT\&T Bell Laboratories, Murray Hill (AT\&T) to evaluate the effect of a $\mathrm{H}_{2}$ plasma pretreatment on GaAs etching. The SNL RIE reactor is a non-load-locked $13.56 \mathrm{MHz}$ rf-powered parallel plate Semi-Group RIE system. The lower electrode is $30.5 \mathrm{~cm}$ in diameter with an interelectrode spacing of approximately $3.8 \mathrm{~cm}$. Samples were also etched at AT\&T in a $13.56 \mathrm{MHz} \mathrm{rf}$-powered parallel plate Oxford PlasmaLab RIE system with a lower electrode diameter of $16.8 \mathrm{~cm}$ and separation of $5.0 \mathrm{~cm}$. The AT\&T RIE chamber was enclosed with a glove box filled with dry $\mathrm{N}_{2}$ to reduce $\mathrm{H}_{2} \mathrm{O}$ in the system. In both reactors samples were attached to a quartz plate, which completely covered the lower electrode, with thermal paste to ensure good thermal conduction. Immediately before loading, the samples were subjected to a $30 \mathrm{sec} \mathrm{NH}_{4} \mathrm{OH}: \mathrm{DI} \mathrm{H}_{2} \mathrm{O}(1: 20)$ rinse.

Nominally matching plasma conditions between the two RIE systems did not yield sinilar etch results; therefore power densities were optimized for each reactor while the pressures and flow rates were held constant for both the $\mathrm{H}_{2}$ and $\mathrm{SiCl}_{4}$ plasmas. In the SNL $\mathrm{RIE}$, the $\mathrm{H}_{2}$ plasmas were run at $335 \mathrm{~mW} / \mathrm{cm}^{2}$ and the $\mathrm{SiCl}_{4}$ plasma etches were run at $80 \mathrm{~mW} / \mathrm{cm}^{2}$. The AT\&T $\mathrm{H}_{2}$ plasma was optimized at $320 \mathrm{~mW} / \mathrm{cm}^{2}$ and the $\mathrm{SiCl}_{4}$ plasma was run at 160 $\mathrm{mW} / \mathrm{cm}^{2}$. Temperature was maintained at $0^{\circ} \mathrm{C}$ and $50^{\circ} \mathrm{C}$ in the $S N L$ reactor and $-16^{\circ} \mathrm{C}$ and $50^{\circ} \mathrm{C}$ in the AT\&T reactor. All pretreatment and etch experiments were run at $20 \mathrm{sccm} \mathrm{H} \mathrm{H}_{2}$ flow rate at a pressure of $20 \mathrm{mTorr}$ and $10 \mathrm{sccm} \mathrm{SiCl} 4$ flow rate at a pressure of $5 \mathrm{mTorr}$.

\section{RESULTS AND DISCUSSION}

\section{A. Etch Rates and Profiles}

The GaAs etch rates for the SNL reactor are $250 \mathrm{~nm} / \mathrm{min}$ at $0^{\circ} \mathrm{C}$ and $300 \mathrm{~nm} / \mathrm{min}$ at $50^{\circ} \mathrm{C}$. The higher etch rate at $50^{\circ} \mathrm{C}$ may be due to increased volatility of the etch products and improved $\mathrm{H}_{2} \mathrm{O}$ removal from the chamber at higher temperatures. In the AT\&T reactor the etch rates are $110 \mathrm{~nm} / \mathrm{min}$ at $-16^{\circ} \mathrm{C}$ and $135 \mathrm{~nm} / \mathrm{min}$ at $50^{\circ} \mathrm{C}$. Comparing the SNL and AT\&T etch rate data shows a much faster etch in the SNL reactor. This is surprising since the SNL reactor is run at one-half the plasma power density of the AT\&T reactor and may be attributed to differences between the two reactors.

GaAs features etched in the SNL reactor are anisotropic independent of temperature and of exposure to the $\mathrm{H}_{2}$ plasma pretreatment (Figure 1a). However, GaAs etching in the AT\&T reactor shows a significant widening at the base of the mesa feature at $50^{\circ} \mathrm{C}$ and no $\mathrm{H}_{2}$ pretreatment (Figure 1b). This profile may be due to reflow of resist at higher temperature and higher incident power density from the plasma since the AT\&T plasma power density is a factor of 2 greater than that used in the SNL reactor. Also, since the GaAs etch rate in the AT\&T reactor is almost a factor of 3 slower than that in the SNL reactor, longer exposure times are necessary to etch to similar depths and may change the resist profile. The profile appears much more anisotropic with a $\mathrm{H}_{2}$ plasma pretreatment suggesting the $\mathrm{H}_{2}$ plasma interacts with the resist to enhance the anisotropy of the GaAs etch (Figure 1c). Low temperature $\left(-16^{\circ} \mathrm{C}\right.$ ) etching in the AT\&T reactor is highly anisotropic independent of the $\mathrm{H}_{2}$ pretreatment (Figure 1d) presumably due to the lack of resist reflow at the lower temperature. 


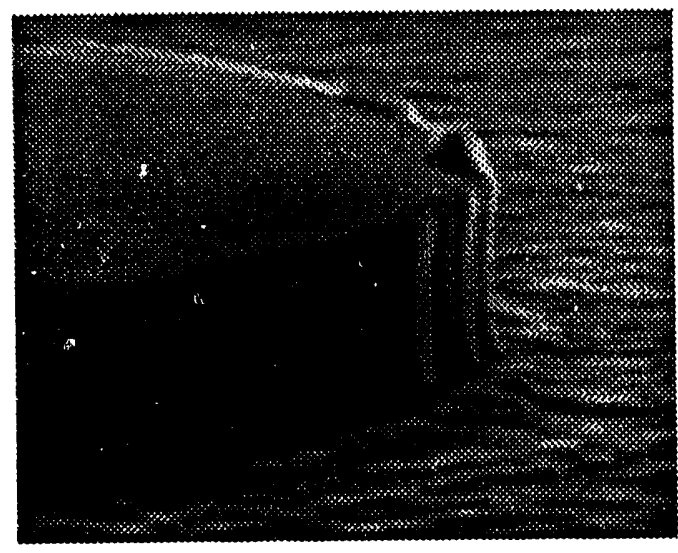

a

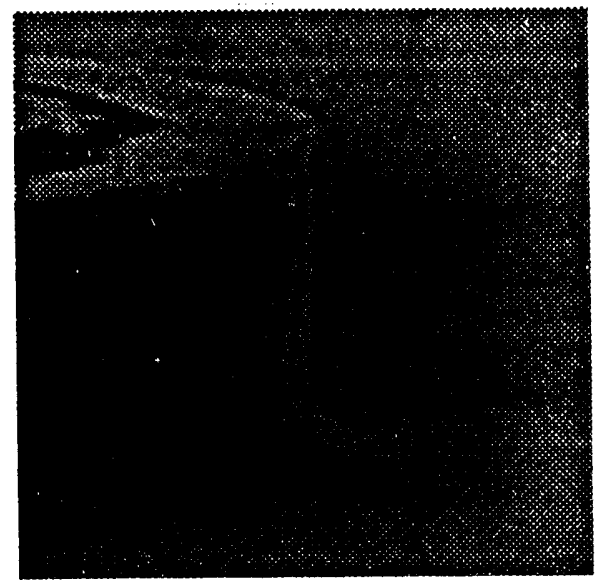

c

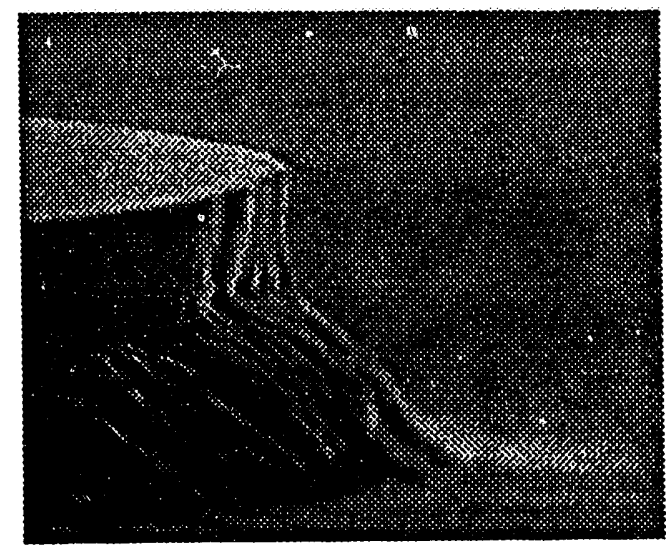

b

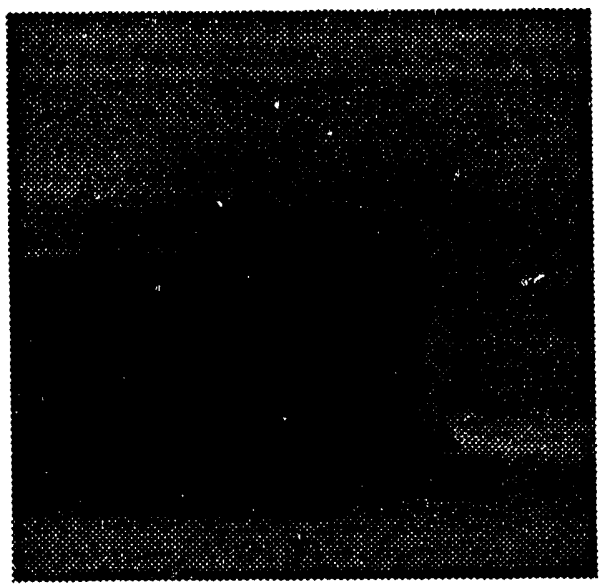

d

Figure 1: SEM micrographs of $\mathrm{GaAs}$ etched in $\mathrm{SiCl}_{4}$ plasma (a) in the $\mathrm{SNL}$ reactor at $50^{\circ} \mathrm{C}$ without $\mathrm{H}_{2}$ plasma exposure $\left(0.75 \mu \mathrm{m}\right.$ deep), (b) in the AT\&T reactor at $50^{\circ} \mathrm{C}$ without $\mathrm{H}_{2}$ exposure $\left(1.7 \mu \mathrm{m}\right.$ deep), (c) in the AT\&T reactor at $50^{\circ} \mathrm{C}$ with 2 minutes of $\mathrm{H}_{2}$ plasma exposure $\left(1.1 \mu \mathrm{m}\right.$ deep), and (d) in the AT\&T reactor at $-16^{\circ} \mathrm{C}$ without $\mathrm{H}_{2}$ exposure $(1.0 \mu \mathrm{m}$ deep).

\section{B. Surface Morphology}

AFM images for surfaces etched in $\mathrm{SiCl}_{4}$ are taken and analyzed for $\mathrm{RMS}$ roughness. The SNL and AT\&T RMS data is shown in Figures 2 and 3, respectively. A patterned, unetched sample has an RMS roughness value of $0.628 \mathrm{~nm}$. In Figure 2, the GaAs samples etched at SNL at $0^{\circ} \mathrm{C}$ and $50^{\circ} \mathrm{C}$ show a decrease in RMS roughness as the $\mathrm{H}_{2}$ exposure is increased to 4 minutes; a slight increase in RMS roughness occurs as the exposure time is increased to 10 minutes. At both $0^{\circ} \mathrm{C}$ and $50^{\circ} \mathrm{C}$, the optimum surface morphology occurs after 4 minutes of $\mathrm{H}_{2}$ pretreatment. The rough etched surface observed at $0^{\circ} \mathrm{C}$ and 1 minute $\mathrm{H}_{2}$ exposure is probably due to incomplete removal of the native oxide, which causes micromasking effects during the $\mathrm{SiCl}_{4}$ plasma etch. As the $\mathrm{H}_{2}$ exposure time is increased, the oxide is more uniformly removed 


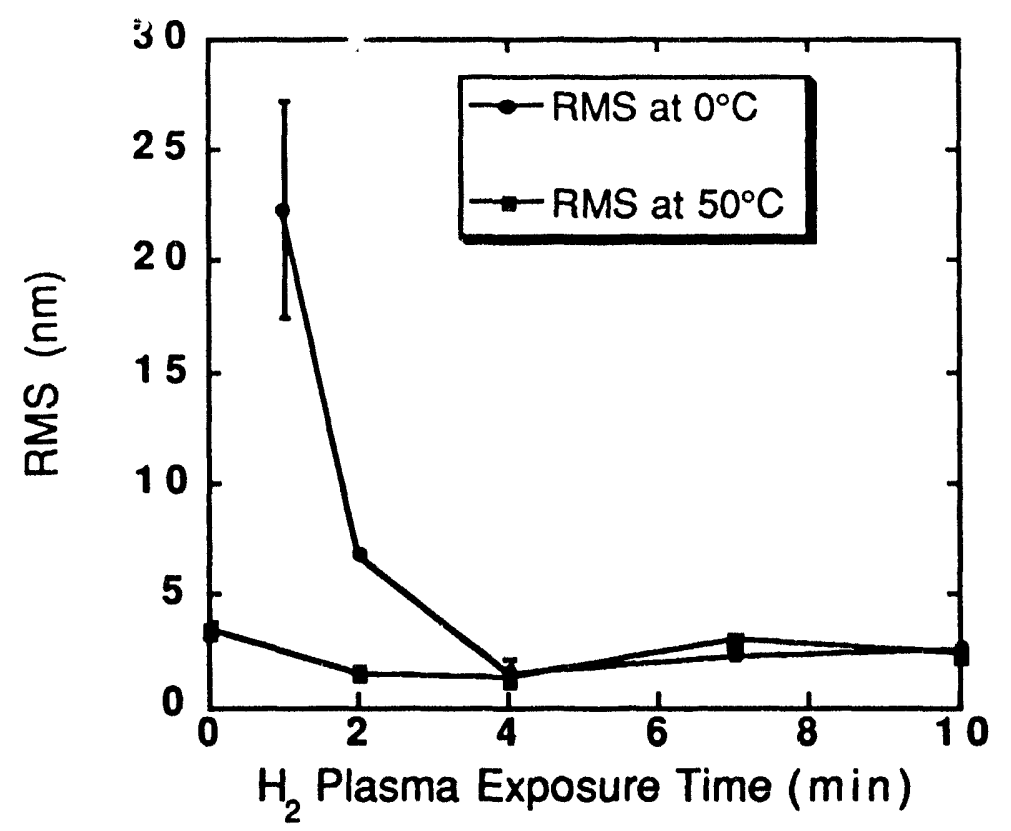

Figure 2: RMS roughness as a function of $\mathrm{H}_{2}$ plasma exposure time for samples etched in the SNL reactor at $0^{\circ} \mathrm{C}$ and $50^{\circ} \mathrm{C}$.

and the RMS roughness improves from $22.4 \mathrm{~nm}$ at 1 minute $\mathrm{H}_{2}$ exposure to $1.51 \mathrm{~nm}$ at 4 minutes $\mathrm{H}_{2}$ exposure. Without exposure to the $\mathrm{H}_{2}$ plasma at $0^{\circ} \mathrm{C}, \mathrm{GaAs}$ etching does not occur in a $80 \mathrm{~mW} / \mathrm{cm}^{2} \mathrm{SiCl} 4$ plasma. However, GaAs etching is achieved when the power density is increased to $160 \mathrm{~mW} / \mathrm{cm}^{2}$ with an RMS roughness of $1.34 \mathrm{~nm}$. This implies that at $80 \mathrm{~mW} / \mathrm{cm}^{2}$, the $\mathrm{SiCl}_{4}$ plasma cannot penetrate the native oxide and initiate $\mathrm{GaAs}$ etching. At $50^{\circ} \mathrm{C}$, the surface morphologies are relatively smooth regardless of the $\mathrm{H}_{2}$ exposure time; however, the RMS roughness improves from $3.47 \mathrm{~nm}$ without $\mathrm{H}_{2}$ exposure to $1.29 \mathrm{~nm}$ with 4 minutes $\mathrm{H}_{2}$ exposure. We also note that the $\mathrm{GaAs}$ etches at $50^{\circ} \mathrm{C}$ without exposure to a $\mathrm{H}_{2}$ plasma. The elevated temperatures may enhance the volatility of the etch products as well as $\mathrm{H}_{2} \mathrm{O}$ removal from the chamber, thereby uniformly removing the native oxide during the $\mathrm{SiCl}_{4} \mathrm{etch}$.

A similar trend is observed for GaAs etching at AT\&T. In Figure 3, we observe an improvement in the etched surface morphology with the addition of the $\mathrm{H}_{2}$ plasma pretreatment. At both $-16^{\circ} \mathrm{C}$ and $50^{\circ} \mathrm{C}$ the optimum surface morphology is observed after a 2 minute $\mathrm{H}_{2}$ exposure. Low temperature etching yields very smooth $\mathrm{GaAs}$ surfaces independent of the $\mathrm{H}_{2}$ pretreatment. The surface morphology improves slightly from $0.986 \mathrm{~nm}$ without $\mathrm{H}_{2}$ exposure to $0.907 \mathrm{~nm}$ with a 2 minute exposure. Comparing the low temperature etching at SNL and AT\&T, we find significant improvement of the surface morphology in the AT\&T reactor at low $\mathrm{H}_{2}$ plasma exposures. We believe the smoother surfaces obtained in the AT\&T etches are due to the effect of the dry $\mathrm{N}_{2}$ glove box which lowers the $\mathrm{H}_{2} \mathrm{O}$ concentration in the chamber and minimizes its effect on removal of the native oxide and $\mathrm{GaAs}$ etching. However, the surface morphologies become similar as the $\mathrm{H}_{2}$ exposure is increased to 4 minutes. The roughest surface morphology in the AT\& $\mathrm{T}$ reactor occurs without $\mathrm{H}_{2}$ exposure at $50^{\circ} \mathrm{C}$. The RMS roughness data is more than an order of magnitude greater than that for the low temperature AT\&T etch without $\mathrm{H}_{2}$ exposure. The smoother surface morphology at low temperature may be due to a lower chemical component of the etch mechanism at $-16^{\circ} \mathrm{C}$. Comparing the high temperature etching at SNL and AT\&T, we see the AT\&T RMS roughness is three times greater than the SNL roughness without $\mathrm{H}_{2}$ 


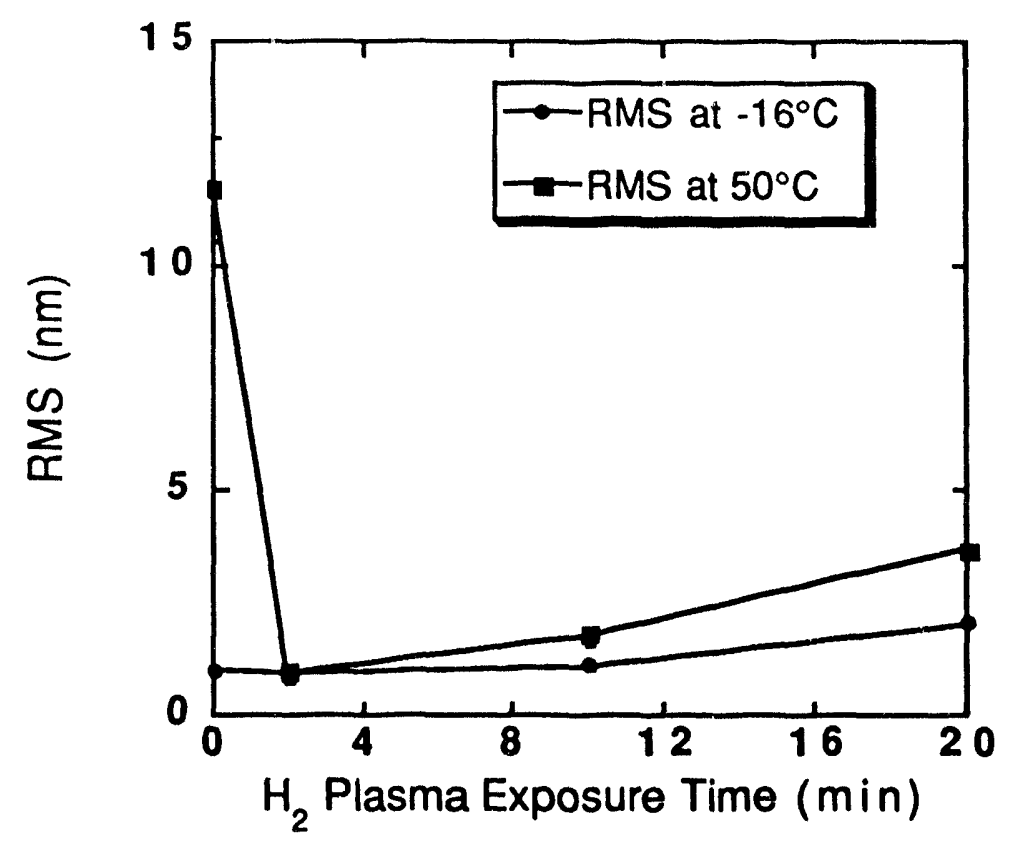

Figure 3: RMS roughness as a function of $\mathrm{H}_{2}$ plasma exposure time for samples etched in the AT\& T reactor at $-16^{\circ} \mathrm{C}$ and $50^{\circ} \mathrm{C}$.

exposure. Since the effect of the glove box is minimized at high temperatures due to lower $\mathrm{H}_{2} \mathrm{O}$ concentrations in the chamber, the higher power density in the AT\&T etch may cause the rougher surfaces. Under all etch conditions studied, the surface morphology seen in the two reactors tends to converge as the $\mathrm{H}_{2}$ exposure is increased.

Several trends can be deduced from this study. First, transferring processes from one reactor to another is difficult. We have observed significant variations in the etch characteristics using "identical" processes in the two reactors. Many of these variations can be attributed to the fact that the AT\&T reactor incorporates a dry $\mathrm{N}_{2}$ glove box which minimizes the $\mathrm{H}_{2} \mathrm{O}$ concentration in the chamber and permits more uniform removal of the native oxide and smooth $\mathrm{GaAs}$ etching. Additionally, differences in interelectrode spacing may effect the ion bombardment energies in the plasma and cause differences in etch characteristics. Etch variations may also be due to differences in thermal contact of the samples to the lower electrode. Second, under all conditions studied we have observed an improvement in the GaAs etched surface morphology with the addition of a $\mathrm{H}_{2}$ plasma pretreatment. The surface morphologies are similar independent of reactor or temperature as the $\mathrm{H}_{2}$ exposure time is optimized ( 2 to 4 minutes in this study). We believe that the slight increase in surface roughness with increasing $\mathrm{H}_{2}$ exposure is due to an interaction between the $\mathrm{H}_{2}$ and the photomask leading to micromasking effects. Also, changing the power density of the $\mathrm{H}_{2}$ plasma from 335 to $165 \mathrm{~mW} / \mathrm{cm}^{2}$ has virtually no effect on the surface morphology of the GaAs etched surfaces suggesting a robust process window for the $\mathrm{H}_{2}$ pretreatment.

\section{CONCLUSIONS}

$\mathrm{H} 2$ pretreatment for 2 to 4 minutes yields a smoother etch morphology and reproducible etch characteristics for $\mathrm{SiCl}_{4}$ etching of $\mathrm{GaAs}$ in two different RIE reactors. Attempts to transfer processes between the two different chambers was not straightforward. However, a $\mathrm{H}_{2}$ plasma 
pretreatment results in improved surface morphology, as quantified with AFM, in both reactors. The $\mathrm{H}_{2}$ plasma selectively removes the native oxide on $\mathrm{GaAs}$ before $\mathrm{RIE}$, resulting in an etch morphology which exhibits significantly less surface roughness since the etching can proceed uniformly through the GaAs.

\section{ACKNOWLEDGMENTS}

The authors would like to thank P.L. Glarborg for her technical support and sample fabrication. This work was performed at Sandia National Laboratories supported by the U.S. Department of Energy under contract \#DE-AC04-94AL85000.

\section{REFERENCES}

[1] K.D. Choquette, M. Hong, R.S. Freund, J.P. Mannaerts, and R.C. Wetzel, J. Vac. Sci. Technol. B9, 3502 (1991).

[2] P. Friedel and S. Gourrier, Appl. Phys. Lett. 42, 509 (1983).

[3] S. Sugata, S. Takamori, N. Takado, K. Asakawa, E. Miyauchi, and H. Hashimoto, J. Vac. Sci. Technol. B6, 1087 (1988).

\section{DISCLAIMER}

This report was prepared as an account of work sponsored by an agency of the United States Government. Neither the United States Government nor any agency thereof, nor any of their Govers or implied, or assumes any legal liability or responsiemplose or usefulness of any information, apparatus, product, or bility for the accuracy, completeness, or use would not infringe privately owned rights. Referprocess disclosed, or represents that its use would not infringe or service by trade name, trademark, ence herein to any specific commercial produc, process or imply its endorsement, recommanufacturer, or otherwise does not necessarily constitute or any agency thereof. The views mendation, or favoring by the United States Goversarily state or reflect those of the and opinions of authors expressed herein do 

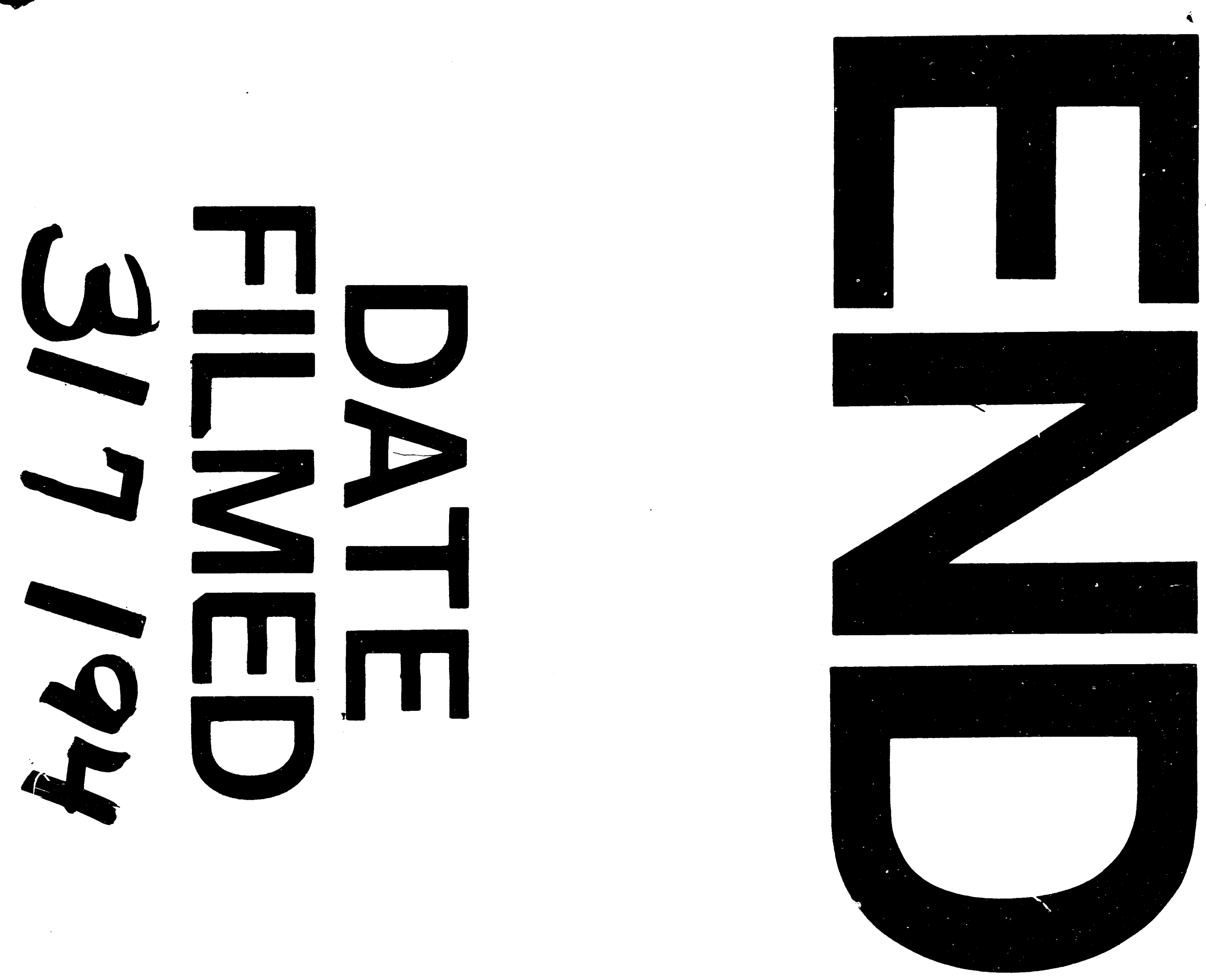


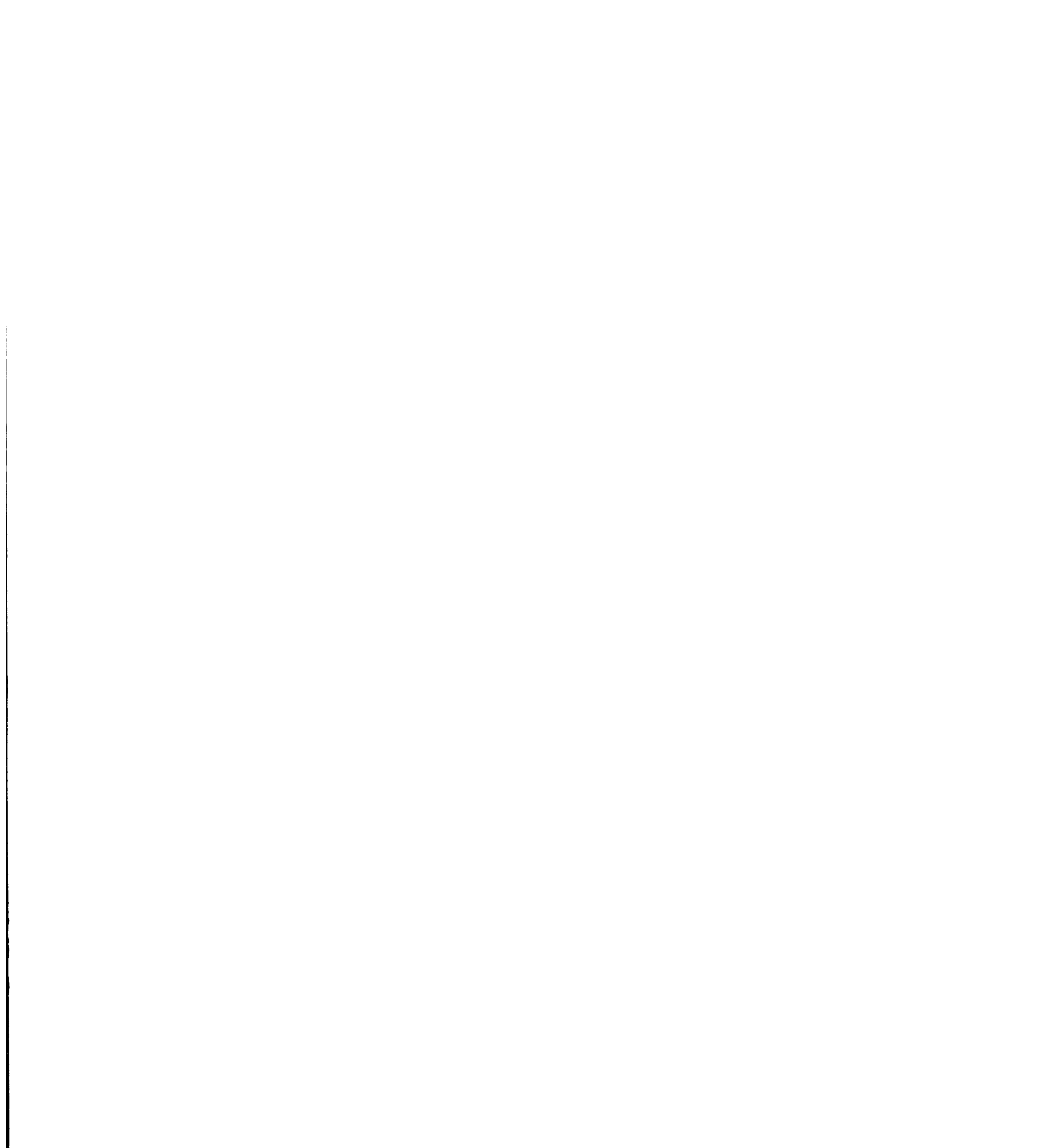

